\title{
En defensa de la realidad espiritual de la inteligencia
}

\author{
In defense of the Spiritual Dimension of Intelligence \\ Franco Fabricio Carpio Chanamé \\ Universidad Peruana Cayetano Heredia, Lima, Perú \\ (iD) https://orcid.org/oooo-0ooz-9058-4876 \\ Correspondencia: franco.carpio.c@upch.pe
}

\begin{abstract}
Resumen
El desarrollo de la neurociencia nos ha permitido comprender mejor el misterio del cerebro y la inteligencia, con sus sorprendentes hallazgos no obstante ha traído consigo el riesgo tentador de materializar de manera absoluta la realidad del ser humano. El presente artículo se presenta como una exposición apologética de la irreductibilidad de la inteligencia a la materia siguiendo el método filosófico. Esta defensa, sin embargo, no se circunscribe a la sola inmaterialidad de esta capacidad humana, sino que pretende hacer explícita la subsistencia o trascendencia de la misma a la luz de la filosofía tomista.
\end{abstract}

Palabras clave: Inteligencia, espiritualidad, alma, realismo psicológico.

\begin{abstract}
The development of neuroscience has allowed us to better understand the mystery of the brain and intelligence which has produced surprising discoveries. However, this understanding has brought with it the tempting risk of the absolute materialization of the human being. This article is presented as an apologetic exposition of the irreducibility of intelligence to matter following the philosophical method. This defense, nevertheless, is not focused only on the no-materiality of this human capacity, instead, it aims to demonstrate its transcendence or subsistence under the light of the tomist philosophy.
\end{abstract}

Key words: Intelligence, spirituality, soul, psychological realism. 


\section{Introducción}

El progreso de la ciencia moderna y su consecuente repercusión en la neurociencia sorprenden al esclarecer, en cierta medida, la complejidad de los procesos psíquico-químicos que actúan en nosotros. Sin embargo, el entusiasmo natural que producen estos hallazgos puede traer consigo el riesgo de olvidar que en el hombre existen caracteres que no se reducen a la materialidad del ser humano.

Este texto se empeña en exponer una reflexión acerca de naturaleza humanay en argumentar, como el título muestra, a favor deuna realidad trascendente en el hombre. Esta exposición, sin embargo, no promete ser exhaustiva ni agotar la explicación de la cuestión del intelecto ni la totalidad del fenómeno psíquico-químico del ser humano. El método es, pues, filosófico y se tratará el objeto de esa manera.

Antes de comenzar la exposición de estas ideas, es preciso establecer algunas nociones presupuestas. El punto de partida es una filosofía denominada realismo moderado, atribuida a Aristóteles y Tomás de Aquino por lo cual suele llamarse filosofía aristotélico-tomista. Si el término aristotélico-tomismo es correcto escapa a los motivos de este discurso, bastará con decir que, desde nuestro punto de vista, esta concepción del mundo explica con sistematicidad y lógica la realidad conocida.

\section{La composición hilemórfica}

El supuesto fundamental es que la realidad existe fuera de nuestra mente y se puede analizar según la composición hilemórfica: hyle-materia, morphé-forma, según la cual se entiende que toda realidad corpórea tiene dos principios constitutivos irreductibles, en el que uno (materia) es la posibilidad de determinación y el otro (forma) es el principio de determinación de la posibilidad real. Por ejemplo, si se considera un roble común (quercus robur), el principio que determina al roble ser roble es la forma substancial, que no se debe confundir con la mera forma geométrica, siendo evidente la variedad de disposiciones espaciales y características externas de los robles. Esta forma substancial informa o determina a la materia, a la cual se le ha llamado prima o primera, para constituir a una substancia corpórea. La materia prima es indeterminada, pura potencialidad, que es capaz de existir sucesivamente en unión con una multiplicidad indefinida de formas, cuando el árbol muere o se desintegra, la materia es informada inmediatamente por otras formas, y es la materia prima la que permite la continuidad en el cambio. Por otro lado, la materia sensible ya se encuentra en sí misma informada, por lo que se le ha llamado materia segunda (Copleston, 1960).

Si se considera a la materia en sí misma se cae en la cuenta que la pura materialidad indeterminada es inconsistente en el ser, la materia en sí misma no explica su configuración o modo de ser o determinación — como se mostrará más adelante-, lo que nos lleva a concluir que materia y forma son principios reales y necesarios de toda realidad corpórea. La relación entre esos dos principios se entiende a la luz de 
la relación de potencia y acto, que son dos modos de ser, en donde encontramos que ser en acto es un ser real cuya posibilidad de ser está de facto existiendo, mientras que la potencia es la posibilidad real de ser ese acto. Esta potencialidad no es una mera abstracción, pues si lo fuera, es decir, sin en efecto solo fuera una construcción lógica y no sustrato ontológico real, la substancia no podría realmente ser en acto; se daría un paso de la nada al ser -o lo que es lo mismo, un salto desde lo simple y llanamente lógico a lo real, error del argumento ontológico-, lo cual es imposible (Artigas, \& Sanguineti, 1993).

Se puede considerar que uno de los puntos más discutibles de ese análisis es la necesidad de acudir al principio "forma", pues la materia podría explicar en sí misma su modo de ser a través de la estructura que recibe en el espacio. Esto puede ser objetado de dos maneras: la primera parte del hecho de que los conceptos de estructura y configuración no son numéricamente idénticos, no son sinónimos reductibles el uno al otro. La estructura se entiende como disposición y orden simpliciter mientras que configuración vendría a ser la disposición de las partes que dan las propiedades a un objeto (Real Academia Española, s/f). Si se considera la mínima realidad material conocida, independientemente de su análisis físico como corpúsculo u onda, no se sigue que por estar dispuestas en un momento y lugar determinados (o distribución de probabilidad según la física cuántica), y necesariamente en virtud de su disposición, se comporten de cierta manera, la materialidad de la cosa y su orden en sí mismos no explican su dinamismo (tampoco la materialidad en sí misma explica su orden), bien podría comportarse de un modo u otro y estas posibilidades son consideradas en virtud de su contingencia. La materia no explica en sí misma este dinamismo, por lo cual es lícito pensar en la necesidad de otro principio "de configuración" que dé razón del dinamismo evidente en la realidad, al cual llamamos forma, de otra manera tendría que aceptarse una realidad estática en este plano.

Sin embargo, ni siquiera una realidad corpórea estática sería posible si negamos este principio inmaterial. Podemos llegar a una razón, ya no en orden a la "operación" o dinamismo de la materia, sino en virtud de su propio existir. Como se había mencionado anteriormente, una materia indeterminada en sí misma es inconsistente en el ser, un dinamismo sin determinación alguna no es posible. El estudio del caos está relacionado con la predictibilidad, con el conocimiento de la determinación, no con la existencia de la misma (Artigas, 2009). En el cambio algo se modifica y algo permanece, de otra forma habría que admitirse una aniquilación y creación continuas. El propio existir de la realidad corpórea (la materia y sus cualidades, energía, temperatura, etc.) exige una determinación en virtud de la que posea la capacidad de cierta operación. ¿Por qué la materia no podría ser principio de su propia determinación? La propia pregunta expone la contradicción de esa propuesta: en el orden ontológico, la causa es anterior al efecto, aunque en el temporal sean realidades instantáneas y simultáneasy/o con origen en la eternidad 
(si se aceptara, como los griegos, la eternidad del mundo), una determinación en el ente corpóreo causa de su propia determinación 1) eliminaría la realidad a determinar (en los entes corpóreos una determinación real no puede existir sin una realidad con posibilidad de ser determinada, como el agua no puede llenar $250 \mathrm{ml}$. de volumen en una taza sin que esa taza como recipiente no existiera y, aunque esa taza esté llena, la posibilidad de estar llena no desaparece aunque esté ya "satisfecha"), 2) en el mismo sentido es ilógico el aceptar que lo causado pueda ser causa de sí mismo y, por último, 3) siendo la materia principio de la potencia, la potencia solo tiene su realidad en relación al acto y nada puede ser en acto y en potencia al mismo tiempo y en el mismo sentido.

Como consecuencia, si pensamos en una realidad material sin un principio de naturaleza (principio estructural y organizativo), que es la forma, nos vemos obligados a negar la pluralidad de los entes. Puesto que una cosa difiere de otra solamente en virtud de lo que tiene de diferentes (valga la redundancia), distinguimos dos entes pertenecientes al mismo género por su diferencia específica (v. gr. la razón en el hombre), cuya expresión se nota en nuestro lenguaje: había notado ya Aristóteles (1994) que definir también es explicar las cosas por las diferencias. Si soloy llanamente existe la materia, sin ningún otro principio que dé razón de ella, no habría distinción real alguna; ya que, aunque, como notaron los escolásticos, el principio de individuación es la materia quantitate signata, la forma al organizarla en una naturaleza cuantificada, dándole una identidad numéricamente distinta, es, en este sentido, principio de individuación sin el cual no existiría multitud de entes (Chevalier, 1968).

\section{La realidad espiritual del alma}

Consideremos ahora al ser humano compuesto de materia y forma. A su forma substancial (que conforma la substancia "hombre") la llamaremos alma. Tomando en cuenta las operaciones más propias del hombre, encontramos las acciones libres (entiéndase no una libertad absolutamente indeterminada, sino la capacidad de autodeterminarse en virtud de un fin y a esa capacidad llamamos libertad), dentro de las cuales podemos enumerar el entender, razonar, elaborar juicios, etc. A este conjunto de acciones se le ha atribuido tradicionalmente como principio inmediato la inteligencia, como potencia operativa del alma (García, 2011).

Esta relación tradicional entre el entender, razonar, etc. y la inteligencia se ha visto desafiada por el gran avance positivo en las neuroimágenes funcionales, que permiten identificar las zonas del cerebro que se activan al emprender estas actividades, por lo cual se ha pretendido reducir la inteligencia a la materia (sistema nervioso).

Lo primero que podemos decir ante este hecho, es que la actividad y el mismo ser de la materia no dan razón de sí fundándose en la propia materialidad exclusivamente, como ya se ha expuesto. Segundo, considerar a las acciones del intelecto como mera representación fenoménica de los 
movimientos de la materia trae consigo dos obstáculos: 1) resolver cómo es que de lo material fluye lo inmaterial y 2) sigue sin explicar el principio de dinamismo de la materia, por lo que no satisface la cuestión. Es pues, razonable, pensar que, a partir del principio inmediato formal, que es la inteligencia, se siguen movimientos materiales, lo cual se encuentra en perfecta armonía con la unión substancial de materia y forma.

Sin embargo, el considerar que las acciones intelectivas se explican por un aliquid —un "algo" - que llamamos inteligencia, en la forma del hombre, a la cual llamamos alma, es decir, en la propia formalidad de la substancia ser humano, no exige en primera instancia su espiritualidad, ya que todo ser corpóreo estaría compuesto de materia y de forma.

\section{Hecho, realidad, verdad}

Pártase de la definición de espiritual, como aquella realidad inmaterial que trasciende al supuesto en el que es o, dicho de otra forma, aquella realidad inmaterial que subsiste (Verneaux, 1970). Para averiguar si la inteligencia es de carácter espiritual, consideremos el objeto de su operación, que es conocer. Para esto debemos, de cierta manera, distinguir entre tres términos a fin de identificar el objeto propio del intelecto: el hecho, la realidad y la verdad.

Definamos un hecho como el evento dado junto y en relación al objeto; es un hecho que, por ejemplo, el lector de este artículo es una persona, que está leyendo este texto y que advierte que conoce esto a través de su entendimiento. Sin embargo, el hecho está determinado en el aquí y ahora, este instante ínfimo que ha transcurrido ya al pasar la mirada por las palabras es objeto propio de los sentidos externos, que presentan esta realidad instantánea a los sentidos internos, y estos generan la percepción del hecho, la memoria, por ejemplo, permite recordar lo que se ha leído párrafos más arriba, dando cierta noción de continuidad a la multiplicidad de hechos, precisamente, continuos, así cuando los sentidos externos tienen su objeto en el aquí y ahora, los sentidos internos (v.gr. memoria) tienen cierta movilidad en el tiempo o tienen su objeto fuera de él en cuanto es irreal (el phantasma o species sensibilis que existe solo en la imaginación). Sin memoria, por ejemplo, sería imposible la noción de cambio y por lo tanto de tiempo (Verneaux, 1970).

En nuestro entendimiento se aprehende una estabilidad mayor que solo lo instantáneo, pero no se aprehende un continuo (por más que tenga estabilidad), lo que nos lleva a considerar una idea más amplia que el simple hecho, a lo cual podríamos llamar realidad, más profunda que el hecho, puesto que el hecho es en cuanto que es en la realidad. Sin embargo, el entendimiento puede aprehender conceptos que no son en sí mismos reales, lo que se evidencia en las ciencias físico-matemáticas: la abstracción de conceptos como un polígono de infinitos lados, la sucesión infinita de números irracionales o de sucesiones continuas, etc., pero ha de tenerse en cuenta que 1) estos objetos son del entendimientoy no de la imaginación, cuyo objeto es la imagen o fantasma de 
lo sensible, es evidente, pues, que no es posible imaginar un polígono de infinitos lados pero sí entenderlo. Además, 2) estos objetos no son tan solo una no-realidad, el valor real no es intrínseco, pero viene dado por la abstracción de - y por tanto en relación a- los hechos presentes en la realidad y a esto podemos llamar verdad. Estos conceptos físicos-matemáticos son verdaderos en cuanto son proporcionados a la realidad, por eso las teorías científicas que prueban estar más adheridas a lo que se observa se imponen ante las anteriores, que se consideran superadas, lo cual ha sido más que evidente en medicina: la verdad que se encuentra en la realidad y se descubre a partir del hecho tiene cierta independencia del momento y el espacio determinados. Que el glaucoma, por ejemplo, sea una enfermedad oftalmológica provocada por aumento de la presión intraocular es tan verdadero ahora como lo fue hace mil años a pesar de que esa verdad no sea evidente de suyo y no haya sido conocida. Que el glaucoma sea esto no depende del momento y las circunstancias en que se descubrió (de hecho, esto se comprende mejor al caer en la cuenta de que se dice des-cubrir y no generar o crear), el hecho en el que se descubrió es la expresión de la verdad y no al revés.

Lo real es necesariamente verdadero, decir que una realidad es falsa es un absurdo, lo que lo real tiene de realidad es en la medida en es que es verdad, no hay pues una existencia falsa, o un ser falso, pero sí decimos que hay un ser que es verdadero. Sin embargo, es de experiencia que la realidad es cambiante y hay cosas reales ahora que antes no eran o que no serán después, por ejemplo, el planeta Tierra no ha existido siempre.

En esto hay que distinguir el plano sensible, por un lado, y el plano metasensible, por el otro. El objeto que tengo frente a mí es ciertamente este en particular, cuando conozco algo me pregunto primero ¿qué es? La respuesta corresponde al plano metasensible de la forma, en virtud de la cual esta cosa es lo que es. Es un árbol, es madera, un hombre, una piedra. De esto hay que aclarar que las realidades sensibles necesariamente tienen materia y forma, por lo que su esencia no solo implica su formalidad, sino también su materialidad. En una segunda inflexión del conocer nos preguntamos ¿qué es esto (esta madera, etc.)? Esta es la madera de la cruz de Cristo, este hombre es Juan, mi padre, etc. Se responde añadiendo los accidentes particulares de lo sensible: por ejemplo: Juan, mi padre, nació en tal día, tal año, vivió durante tanto tiempo fue enterrado en tal lugar, son hechos comprendidos en la realidad que es mi padre.

Ahora bien, ha de notarse que comprender toda esta realidad sensible presupone comprender realidades en abstracto o, si se quiere, formales: qué es hombre, qué es tiempo, qué es un día, etc. A través del hecho de este hombre, Juan, descubro una realidad, y, digamos, una doble expresión de la verdad, en lo sensible y lo formal. Todo se aprehende en razón de algo verdadero y no en razón de algo falso, ya que saber lo falso supone lo verdadero sin lo cual no se conoce la razón de falsedad. Así, una vez que Juan muere, su existencia, 
que se ha aprehendido como verdadera, no es falseable, seguirá siendo verdadera a pesar de todos los eventos indeterminados posteriores. Hay que notar que el tiempo permite la generación de verdades, ya que, por ejemplo, un nuevo hombre es una realidad inédita (Yepes, 1997), permite su puesta en acto, pero no las elimina. Una verdad no puede volverse falsa y suponiendo que así fuera, sería ininteligible en razón de lo cual no se puede aprehender lo falso primariamente. Por eso, el cambio o el movimiento no elimina que la verdad sea, independientemente de su expresión circunstancial para nosotros, a pesar de que lo sensible cambie. Nada impide, además, que una verdad sea accesible a la inteligencia en el tiempo como efecto de una causa o como causa de un efecto.

\section{El objeto metasensible y universal de la inteligencia}

Puede decirse, entonces, que hay realidades más universales y otras más concretas. Esta universalidad se daría, según pensamos, en razón de la mayor identificación con lo verdadero, lo concreto, por su parte, en razón de la mayor identificación con el hecho (cuya verdad se descubreal discurrir por la realidad, aunque no se haga conscientemente, se acepta generalmente y se ha planteado como marco teórico que los hechos son reales). Así, este libro, este gato, esta casa son realidades que tienen en sí una verdad, aunque esa realidad sea contingente, mas esto no es una cuestión principal en el tema a tratar aquí en cuanto que se puede exponer que podemos conocerverdades universales en su independencia de un espacio-tiempo determinado.
Esto se observa al considerar la misma realidad cambiante: los seres corpóreos son contingentes. Son, pero pueden no haber sido, la realidad es que, al pensar en ellos, descubrimos la verdad de que son y la verdad de que su existencia no es necesaria en sí misma, pues vemos que el mundo constantemente cambia ya que no es de necesidad absoluta. El pensar que el mundo no fue alguna vez no hace más que confirmar esta proposición, si no fue y es ahora, entonces es contingente, pero ¿en dónde estaría la verdad del mundo antes de existir? No hay un antes si no hay tiempo. Por otro lado, se puede cuestionar esta conclusión con base en la presunción de la eternidad del mundo, sin embargo, «si todas las cosas tienen la posibilidad de no ser, esta posibilidad debería realizarse inevitablemente en el tiempo infinito» (Copleston, 196o, p. 135). Por lo que existen conclusiones que se presentan como inevitables, y de estas conclusiones la inteligencia aprehende su verdad. En el caso que a nosotros respecta, que el mundo no es subsistente por sí. De esta forma se pone en evidencia que es posible la concepción de una verdad independiente del tiempo, ya que la materia al ser principio de indeterminación no se puede alienar de la contingencia. Podemos aprehender la verdad, que no es más que la actualidad de la cosa (del acto metafísico), que en tanto que dada la actualidad infalseable esta verdad aprendida es inalienable e independiente. Cuanto más nos acercamos a las estructuras ontológicas de la realidad, esto resulta mucho más radical y evidente. Dado que el ser, y en consecuencia toda actualidad, pues no podemos ser nada si antes no somos 
(no puedo ser médico sin antes simplemente ser), nos viene dado a través de la forma (que nos "organiza"), para que la realidad sea, en cualquier sentido necesita un principio formal, necesita estar en acto. Acaso nos damos cuenta de la trascendencia del hecho expresado en la simplísima frase "algo es". Lo mismo se puede decir de los primeros principios o de que el todo es mayor que la parte. Son verdades universales. En estas verdades que gozan de independencia físico-temporal y que son objetos de la inteligencia, la inteligencia conoce lo universal. Lo cierto es que la aprehensión de la verdad sucede siempre en un plano real fuera de lo sensible, es decir de lo espacio-temporal, aunque tenga relación con ello. Esto merece una breve explicación: naturalmente el hombre conoce de manera más propia los entes sensibles, dado que la naturaleza humana es corpórea, al respecto escribiría Tomás de Aquino: «Potentia cognoscitiva proportionatur cognoscibili. Intellectus humani, qui est coniuctus corpori, propium obiectum est quidditas sive natura in materia corporalis existens et per huiusmodus naturas visibilium rerum etiam in invisibilium rerum aliqualem cognitionem ascendit» (Summa Theologiae I, 84, 7). Así pues, el objeto material del conocimiento humano es la suma de todos los objetos conocibles, de forma primaria los entes sensibles, pero todo esto no podría ser conocido si no por un principio de adecuación de la cosa y el intelecto, aquello que la hace inteligible. En instancia última, este principio es que la cosa sea, su esse, ya que nada cae bajo el entendimiento si no es sub ratione entis (Verneaux, 1970). No aprehendemos algo que no sea, algo que no tiene esse es la nada y la nada no es, pues, algo.

Ahora bien, el concepto se encuentra abstraído de caracteres individuales. Cuando conozco lo que es un hombre, no solo conozco a este hombre sino, además, el universal hombre, aplicable a todos los hombres particulares. No sería aplicable a una multiplicidad de entes si es que, en efecto, no estuviera abstraído de los caracteres sensibles. Este hombre que conozco es real y el concepto "hombre" que he aprehendido también lo es, pues es algo del hombre lo que conozco. Si dijera que el concepto es de la imaginación y por tanto algo no real, aceptaría la imposibilidad de conocer las cosas, sino tan solo la idea que tengo de ellas, una idea de algo que no sé qué es y de lo cual no podría saber tampoco que es. En fin, el conocimiento sería imposible.

Que el objeto de la inteligencia sea universal no significa, sin embargo, que el hombre tenga un conocimiento universal (es decir de todo lo que es posible conocer) ni que tenga un conocimiento absoluto de las realidades, el conocimiento del objeto no implica la posesión intelectual total del mismo, por ejemplo, sé qué es el mar, pero no sé cuál es el volumen de agua que contiene, cuál es la proporción de sus minerales, etc. El hombre siempre puede conocer más y mejor. Esto tampoco implica que el hombre no tenga conocimiento de las realidades individuales, pues lo cognoscible es su objeto y lo particular es ciertamente cognoscible: conozco este libro, esta casa, etc. Lo que lo hace posible es que quien conoce es el ser humano y 
este tiene sentidos, que tienen por objeto lo concreto, además de alguna forma la inteligencia también puede conocer lo particular, cosa que no será tratada aquí. Baste citar una frase que expresa lo dicho: species non est id quod cognoscitur sed id quo obiectum cognoscitur.

\section{La subsistencia de la inteligencia}

Después de considerar el objeto de la inteligencia se puede conocer, por lo menos, algo de su naturaleza. Proseguimos en consonancia con la sentencia escolástica operatio sequitur esse: la operación (efecto) debe ser proporcional al principio operativo (causa). Dado que el objeto y la operación (la inteligencia como potencia del alma es inmaterial, por tanto, su movimiento, el inteligir o conocer, también lo es) son en sí mismos inmateriales, con toda abstracción de lo sensible, en última instancia, sin materia y sin quando, se sigue que la inteligencia no dependa en sí misma del cuerpo. La dificultad en dar un rápido asentimiento a esta conclusión radica en el hecho evidente de que cuando existe afectación del cuerpo, propiamente del sistema nervioso central, existe también defecto o imposibilidad de raciocinio. Debe haber pues un tipo de relación entre el entendimiento y la materia, pero esa relación no podría ser de dependencia intrínseca, según lo que se ha expuesto, entonces esta dependencia tendría que ser extrínseca. La respuesta de Tomás de Aquino es resolver esta cuestión en la imaginación: «Es esencial a la naturaleza visible el existir en un individuo que no es tal sin materia corpórea (...). Por lo tanto, no se puede conocer verdadera y completamente la naturaleza de cualquier objeto material si no se la conoce como existente en concreto. Pero lo particular lo percibimos por los sentidos y la imaginación. Para que el entendimiento entienda en acto su objeto es necesario que recurra a las imágenes de la fantasía a fin de descubrir la naturaleza universal existiendo en un objeto singular» (S. Th. I, 84, 7). Lo que es consecuencia de que nihil est in intellectu quod non prius fuerit in sensu. Conocemos pues, lo universal desde lo particular, lo cual es proporcional a nuestra naturaleza humana, y por tanto corpórea, según se ha dicho.

Otro hecho interesante se encuentra en la capacidad reflexiva de la inteligencia. En efecto la inteligencia conoce que conoce, cosa que no sucede con las facultades sensibles, ni si quiera con la imaginación pues ella no puede imaginar su imaginar, a pesar de desarrollar la más alta abstracción posible en el hombre en el plano sensible. Imaginar es recrear una imagen de un fenómeno sensible (de ahí que no se puedan imaginar conceptos únicamente inteligibles como la forma, la esencia, Dios, etc.), el imaginar no es sensible, por lo tanto, no se puede imaginar el propio imaginar. Esto es característico de este tipo de facultades, sensibles, las cuales dependen intrínsecamente de la materia, puesto que la operación sigue al ser, si la forma de ser es material, la operación intrínsecamente será dependiente de la materia, pero la materia no es reflexiva, no puede volverse sobre sí misma, de la forma en que los ojos no ven que ven, la mano no siente su tacto, etc. Por lo tanto, si la inteligencia es reflexiva, no depende intrínsecamente de la materia. 


\section{Conclusiones}

Lo expuesto no es más que consecuencia de que todo conocimiento y noción de realidad se resuelve en el ente (Alvira et al., 1989). La noción más primaria de la realidad es ser, y si se considera el ser en sí mismo no es, en efecto, determinado por una realidad espacio temporal, el ser simpliciter, a diferencia de las creaturas quienes somos composición de ser y esencia. Gracias a esta noción analógica del ente podemos conocer todo lo que es, ya que ens et verum convertuntur (Alvira et al., 1989), siendo que lo que es, es en tanto es verdadero, no es de extrañarse que, ya que es el objeto de la inteligencia, esta verdad sea universal.

Una cuestión que suscita este análisis es, sin duda, la inmortalidad. Podríamos decir que, si es que la inteligencia subsiste sin la materia, nada obliga a que esta desaparezca luego de que perezca el cuerpo, y dado que la facultad es del alma, el alma no tiene por qué perecer. Sin embargo, la inmortalidad en sí misma es un problema también. Ser y no morir, ¿para qué?

Mas la consecuencia inevitable de esta breve reflexión es preguntarse qué hay de ese ser simpliciter, si la inteligencia tiendea loverdadero, inexorablemente tiendeal ser sin más, en tanto tiende la facultad, tiende también el supuesto. El hombre tiende a una plenitud deverdad, llámese si sequiere, de felicidad, teniendo en cuenta lo dicho por Marías (1980) citando al Estaragita: «Aunque se es hombrey mortal, no hay que tener - dice Aristóteles - sentimientos humanos y mortales, sino que es menester inmortalizarse en lo posible y vivir de acuerdo con lo más excelente que hay en nosotros, aunque sea una exigua porción de nuestra realidad. Lo más excelente es lo más propio de cada cosa, y sería absurdo no escoger la propia vida si no la de algún otro» (Aristóteles, 1985, p. 78).

Así pues, esta tendencia a la felicidad, lejos de ser —como quizás diría Sartre (1993) - “una pasión inútil", se descubre como todo lo contrario al saber que nuestra naturaleza se inclina hacia esa verdad fundamento de las verdades gracias a nuestra inteligencia espiritual.

\section{Financiamiento}

La realización del artículo no recibió financiamiento externo.

\section{Conflictos de interés}

El autor declara que no tiene conflictos de interés. 


\section{Referencias}

Alvira, T., Clavell, L., \& Melendo, T. (1989). Metafísica. EUNSA.

Aristóteles. (1985). Ética a Nicómaco. Gredos. (J. Pallí Bonet, Trad.)

Aristóteles. (1994). Metafísica. Gredos. (T. Calvo Martinez, Trad.)

Artigas, M. (2009). Filosofía de la ciencia. EUNSA.

Artigas, M., \& Sanguineti, J. J. (1993). Filosofía de la naturaleza. EUNSA.

Aquino, T. de (2011). Suma Teológica, Vol. III. BAC.

Chevalier, J. (1968). Historia del pensamiento, Vol. I. Aguilar.

Copleston, F. (1960). El pensamiento de Santo Tomás. Fondo de Cultura Económica.

García, J. A. (2011). Antropología filosófica. EUNSA.

Marías, J. (1980). Historia de la filosofía. Revista de Occidente.

Real Academia Española. (s.f.). Diccionario de la Lengua Española, 23ava. ed. https:// dle.rae.es

Sartre, J. (1993). El ser y la Nada. Editorial Losada.

Verneaux, R. (1970). Filosofía del hombre. Herder.

Yepes, R. (1997). La persona y su intimidad. EUNSA.

Recibido: 1 de octubre de 2020

Revisado: 11 de marzo de 2021

Aceptado: 16 de mayo de 2021 